\title{
Evaluation and Optimization for Joint Disaster Response of Public Space and Public Service Facilities in Metropolises: Taking Chongqing City as an Example
}

\author{
Yuan Xinyi ${ }^{1, ~ *}$, Han Ying ${ }^{1}$, Xu Hanjing ${ }^{1}$, Hong Yang ${ }^{2}$ \\ ${ }^{1}$ Faculty of Architecture, Southeast University, Nanjing, China \\ ${ }^{2}$ Faculty of Creative Engineering Research, Waseda University, Tokyo, Japan \\ Email address: \\ yuanxinyi1234@gmail.com (Yuan Xinyi), 2386190641@qq.com (Han Ying) \\ ${ }^{*}$ Corresponding author
}

\section{To cite this article:}

Yuan Xinyi, Han Ying, Xu Hanjing, Hong Yang. Evaluation and Optimization for Joint Disaster Response of Public Space and Public Service Facilities in Metropolises: Taking Chongqing City as an Example. Urban and Regional Planning. Vol. 6, No. 3, 2021, pp. 101-111. doi: $10.11648 /$ j.urp. 20210603.13

Received: August 24, 2021; Accepted: September 16, 2021; Published: September 23, 2021

\begin{abstract}
The outbreak of Covid-19 pandemic has had a dramatic impact on the order of cities around the world. Among them, metropolises are more vulnerable to such public health incidents due to dense urban environments and complex human activities. It is crucial to improve disaster prevention capabilities of metropolises. In metropolitan areas with limited land resources, the cost of building dedicated disaster prevention facilities is high. Therefore, when a significant disaster strikes, urban public space and public service facilities are often converted into temporary emergency rescue places to assist the urban disaster prevention system, which is an essential line of defense to ensure urban safety. However, urban public space and public service facilities have their own resource shortcomings in emergency rescue, and if they can cooperate to respond to disasters by sharing resources, they can further improve their emergency response capacity during disasters. This paper took the main downtown districts of Chongqing as the research object, based on the POI data and ArcGIS, evaluated the coordination of spatial layout and the level of spatial connection between public space and public service facilities, analyzed the difficulties and causes of Joint Disaster Response of the two, and finally proposed optimization suggestions in order to provide new ideas for disaster prevention and mitigation in the post-Covid-19 era in Metropolises.
\end{abstract}

Keywords: Urban Disaster Prevention, Public Space, Public Service Facilities, POI, ArcGIS

\section{Introduction}

With the outbreak of the Covid-19 pandemic in 2019, urban medical and emergency systems were tested. And the urban life, economy and order were severely affected simultaneously [1]. Currently, the mutated virus, which is more contagious and lethal, is spreading in various places. The global situation of prevention is still grim. This makes the people's appeal for enhancing the urban emergency rescue capabilities more urgent $[2,3]$.

The metropolis, which is characterized by a large population, high building density, and limited resources, is more vulnerable in public health incidents [4, 5]. High-density urban environment is usually accompanied by complex human activities, which increases the probability of public health incidents, and it is difficult to trace the source of infection [6]. Limited space and resources in metropolises make public space and public service facilities become essential parts of the urban comprehensive disaster prevention system [7, 8]. However, public space and public service facilities have their own shortages in disaster response, which can be overcome through cooperation in sharing space resources and energy supplies. So the urban comprehensive disaster response capacity can be effectively improved by sharing resources of public space and public service facilities.

As a result, the coordination between public space and public service facilities can reflect the urban disaster relief capacity to a certain extent and it is necessary to evaluate it. Taking Chongqing City as an example, this paper put forward the concept of Joint Disaster Response (sharing of resources 
during disasters) and, and developed a method of evaluation for Joint Disaster Response capacity. It aimed to clarify the shortcomings of urban disaster relief in the current stage and provide optimization directions and planning strategies for the urban disaster resilience of metropolises in post-Covid-19 era.

\section{Joint Disaster Response Capacity Between Public Spaces and Public Service Facilities in Metropolises}

\subsection{Public Space and Public Service Facilities Are an Essential Line of Defense Against Disasters in Metropolitan Areas}

The metropolis is an advanced stage of urban development, which is characterized by a large population size, high urbanization level, and strong links with surrounding regions [9]. It is impracticable to build abundant dedicated spaces for disaster prevention because of the limited land resources and high land prices in metropolitan areas. Therefore, when a disaster occurs, urban public space and public service facilities will be transformed into temporary rescue places for urban disaster prevention and share the task of urban disaster relief [10]. During the outbreak of the COVID-19 pandemic, urban green belts and large parks were essential barriers to prevent the spread of the epidemic [11]; urban squares and other open spaces were used as parking lots and goods transfer areas in disaster relief [12]; cultural centers, large venues, and university dormitories were converted into temporary hospitals to decrease the burden of the urban medical system [13]; groceries, supermarkets, and farmer's markets provided daily living supplies for communities to ensure smooth implementation of home quarantine [14].

When a significant disaster strikes, public space can provide rescue places, and public service facilities can provide support resources, both of which play a crucial role in maintaining the normal operation and order of the metropolis.

\subsection{Joint Disaster Response of Public Space and Public Service Facilities Can Improve Disaster Prevention Capabilities in Metropolises}

Natural disasters and public health events in different places have made academic circles realize that open or semi-open urban public space and public service facilities such as parks, squares, streets, sports arenas, and schools have apparent disaster-resistant performance. However, the lack of materials, facilities, and equipment resources significantly impairs emergency rescue capabilities of urban public space. The lack of parking, transport and assembly spaces makes it difficult for public service facilities to rescue during disasters. Because of the limitations of urban public space and public service facilities in disaster response, the author proposed the concept of "Joint Disaster Response" to make use of both functions, and to meet the urban needs during disasters.

The Joint Disaster Response of urban public space and public service facilities, i.e., resource sharing during disasters, means that when a disaster strikes, urban public space can be quickly transformed into rescue places to provide space expansion for public service facilities; while urban public service facilities can quickly provide resources and equipment supplies for emergency rescue spaces. Under the model of the Joint Disaster Response, public spaces such as squares, city parks, parklands and sports arenas can be converted into parking lots and resource storage areas to provide spatial expansion support for public service facilities involved in emergency rescue; similarly, urban public service facilities such as shopping malls, community centers, cultural centers and universities can provide medical resources, living supplies, and energy resources for public spaces involved in emergency rescue (Figure 1). Public space and public service facilities can share resources with each other through Joint Disaster Response model to overcome their own resource shortcomings and further improve the emergency rescue capacity of metropolises.

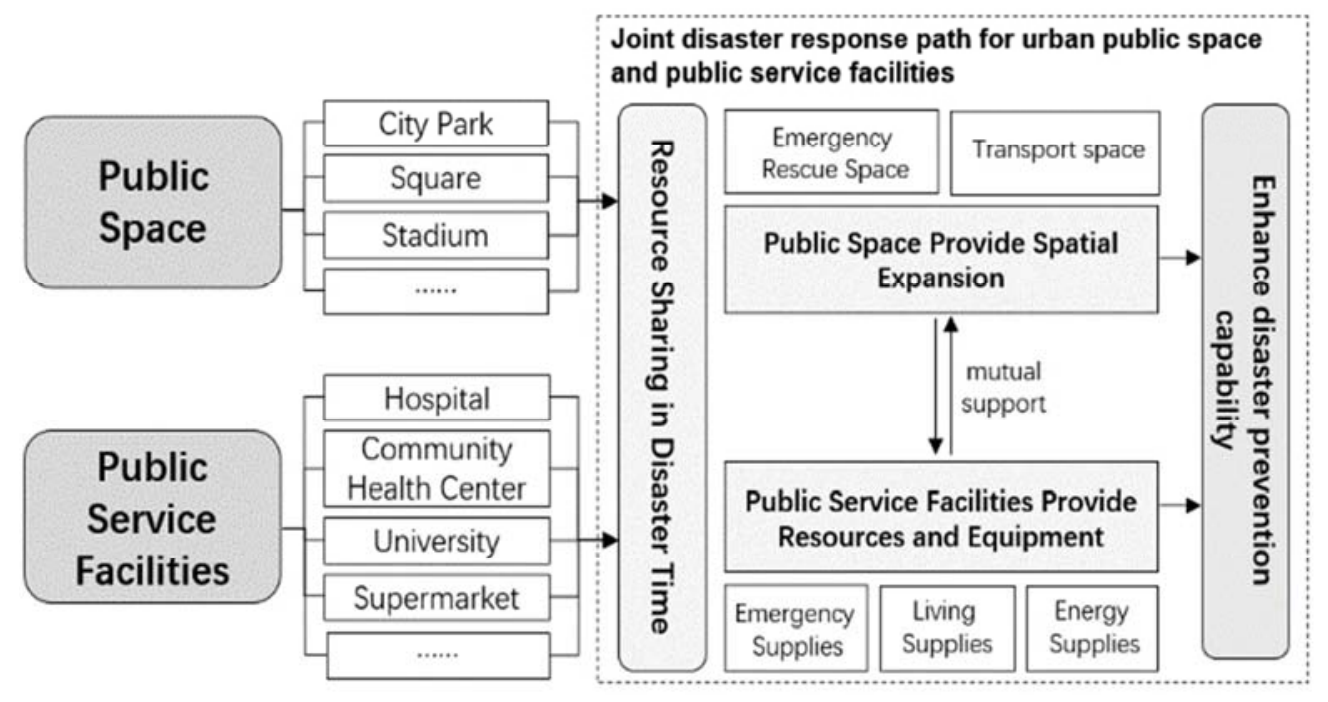

Figure 1. Joint Disaster Response path for urban public space and public service facilities. 


\section{Research Objects and Methods}

This paper took the main downtown areas of Chongqing as an example to evaluate the Joint Disaster Response capacity of public space and public service facilities.

\subsection{Selection of Research Objects}

The author selected the main downtown districts of Chongqing as the research object for the study. Chongqing City is a metropolis with a resident population of $32,054,200$. The main downtown districts of Chongqing, including Yuzhong District, Jiangbei District, Nanan District, Yubei District, Shapingba District, Dadukou District, Jiulongpo District, Banan District, and Beibei District (Figure 2), covers an area of about $28,657 \mathrm{~km}^{2}$ and has a population of about 10.34 million (data from the seventh census). Due to the high population density, all nine districts in the main downtown districts of Chongqing were included in the high-risk districts in the "Implementation Plan for the Prevention and Control of the COVID-19 Pandemic Disease by Epidemiological Zone Classification in Chongqing City (2020)" [15]. As a high-density metropolitan area, the overlap of public health events and human activities can significantly aggravate the damage and impact of epidemics in Chongqing [16], and the evaluation of its disaster prevention space and facilities has an instructive significance for metropolitan disaster mitigation efforts.

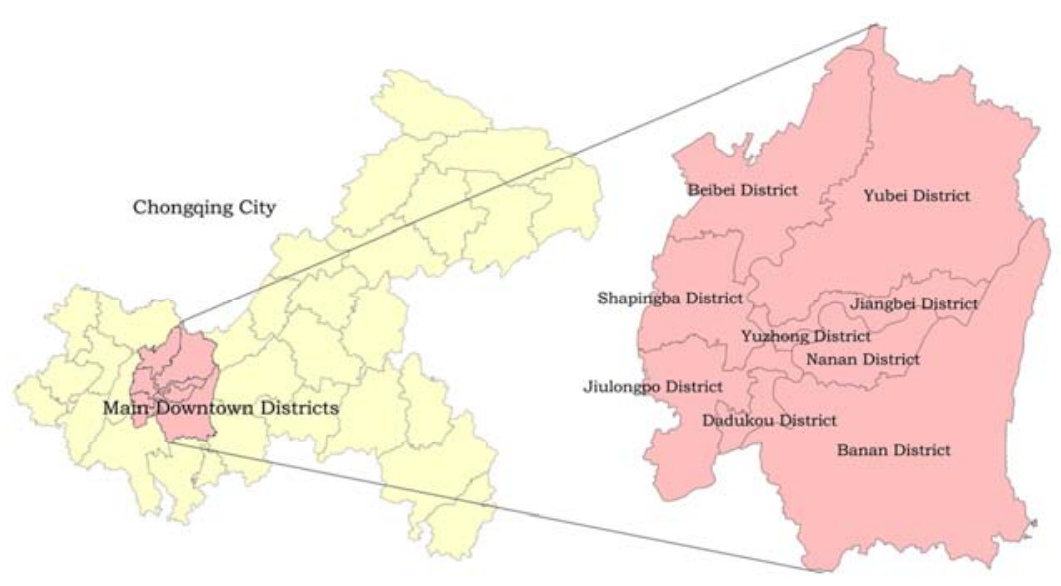

Figure 2. Map of nine districts in the main downtown districts of Chongqing.

\subsection{Research Methods and Ideas}

\subsubsection{Research Framework}

The author developed a research framework for the Joint Disaster Response evaluation of public space and public service facilities in Chongqing from three aspects: evaluation process, element system and data level (Figure 3).

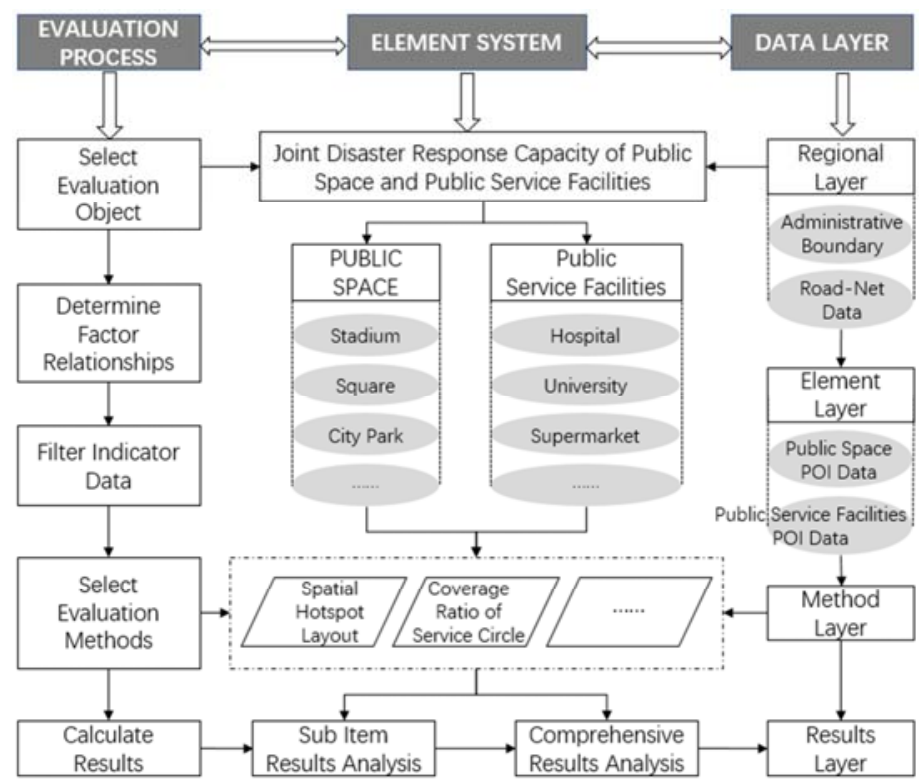

Figure 3. Framework of Joint Disaster Response study for public space and public service facilities. 


\subsubsection{Element Selection and Data Collection}

This paper focused on urban public space and public service facilities with disaster emergency rescue capabilities in the face of public health events. Therefore, three types of large open public space, namely parks, squares, and stadiums, and six types of public service facilities that can provide medical or living supplies, namely hospitals, community health centers, universities, farmers' markets, supermarkets, and large cultural facilities (museums, science and technology centers, art galleries, libraries and exhibition halls) were selected for the study.

The data of public space and public service facilities came from Baidu Map's POI (Point of Interest) data, which was a basic point data representing urban space facilities and was widely used in studying the spatial distribution of facilities [17, 18]. The author used Baidu API to extract and sift various POI data of above-mentioned public space and public service facilities within the main downtown districts of Chongqing, and the results were shown in Table 1.

Table 1. Classification and quantity of elements.

\begin{tabular}{lll}
\hline Categories & Sub-Categories & Quantities \\
\hline \multirow{3}{*}{ Public Space } & Square & 253 \\
& City Park & 340 \\
& Stadium & 108 \\
& Hospital & 125 \\
Public Service & Farmers' Market & 359 \\
Facilities & Community Health Center & 229 \\
& University & 69 \\
& Supermarket & 4067 \\
& Large Cultural Facility & 482 \\
\hline
\end{tabular}

\subsubsection{Evaluation Method}

Based on ArcGIS, the author evaluated the Joint Disaster Response capacity of public space and public service facilities from two aspects: the coordination of spatial layout and the level of spatial connection. The coordination of spatial layout was obtained by conducting the Kernel Density Estimation of public space and public service facilities and comparing both spatial hotspots; the level of spatial connection was obtained by measuring the coverage ratio of various public service facilities in the service scope of public space under the road network and combining with the analysis of the specific case.

(1) Comparison of Kernel Density Estimation between public space and public service facilities based on POI data.

In order to evaluate the coordination of spatial layout of public space and public service facilities, various types of the POI data of public space and public service facilities in the main downtown districts of Chongqing were separately integrated, and the Kernel Density Estimation was conducted by ArcGIS to extract spatial hotspots of both and judge the degree of overlap.

(2) Measure the coverage ratio of various public service facilities in service scope of public service facilities based on POI data.

In order to evaluate the level of spatial connection between public space and public service facilities, the author developed the service scope centered on public space to measure the coverage ratio of various public service facilities in different downtown districts of Chongqing. The specific calculation methods were as follows: the POI data of public space and the road-net data was used to conduct Network Analyst based on ArcGIS to obtain the 500-meter reachable range of public space under the actual road network; the coverage ratio of various public service facilities in different downtown districts of Chongqing was calculated based on the POI data of public service facilities and the following formulas. If the class-k public service facility $\left(\mathrm{F}_{\mathrm{k}}\right)$ is within the public space (PublicSpace $\mathrm{i}_{\mathrm{i}, \mathrm{s}}$ ) 500-meter scope, as shown in formulas (1)-(3).

$$
\begin{gathered}
P_{i, k, s}=\left\{\begin{array}{c}
1, \exists F_{k} \subset N_{1}\left(\text { PublicSpace }_{i, s}\right) \\
0, \text { others }
\end{array}\right. \\
P R_{i, k}=\frac{\sum_{s=1}^{P_{i}} P_{i, k, s}}{P_{i}} \\
T P R_{k}=\frac{\sum_{i=1}^{21} \sum_{s=1}^{P_{i}} P_{i, k, s}}{\sum_{i=1}^{21} P_{i}}
\end{gathered}
$$

Thereinto, PublicSpace ${ }_{i, s}$ denotes the public space-s in street-i, and $\mathrm{P}_{\mathrm{i}, \mathrm{k}, \mathrm{s}}$ denotes the existence or nonexistence of public service facility $F_{k}$ within 500-meter scope of PublicSpace $_{i, s}$, and the existence means to be covered. $\mathrm{PR}_{\mathrm{i}, \mathrm{k}}$ denotes the coverage ratio of public service facilities- $F_{k}$ in the i-th urban district, which represents the coverage level of different urban districts, and $\mathrm{P}_{\mathrm{i}}$ denotes the quantity of public space in the $\mathrm{i}$-th urban district. $\mathrm{TPR}_{\mathrm{k}}$ denotes the coverage ratio of public service facility- $\mathrm{F}_{\mathrm{k}}$ in the city, which represents the overall coverage level of the city.

\section{Evaluation Results of Joint Disaster Response between Public Space and Public Service Facilities}

\subsection{The Coordination of Spatial Layout Between Public Space and Public Service Facilities Was Weak}

The distribution of various public space and public service facilities in the main downtown districts of Chongqing according to POI data was shown in the figure below (Figure 4). It could be seen that the distribution of public space in the main downtown districts of Chongqing was comparatively average with small-scale gatherings. The public space mainly distributed in the periphery of old urban areas, such as the southern part of Yubei District, the western part of Banan District, the eastern part of Jiulongpo District and the western part of Nanan District, but in the center of old urban areas, such as Yuzhong District and Jiangbei District, it was seriously insufficient. While the distribution of public service facilities in the main downtown districts of Chongqing was quite uneven with the large-scale gathering, mainly concentrated in the old urban areas, such as Yuzhong District, the western part of Jiangbei District, the western part of Nanan 
District, the eastern part of Shapingba District, the eastern part of Jiulongpo District and the northern part of Dadukou District, but the public service facilities were inadequate in new urban areas.

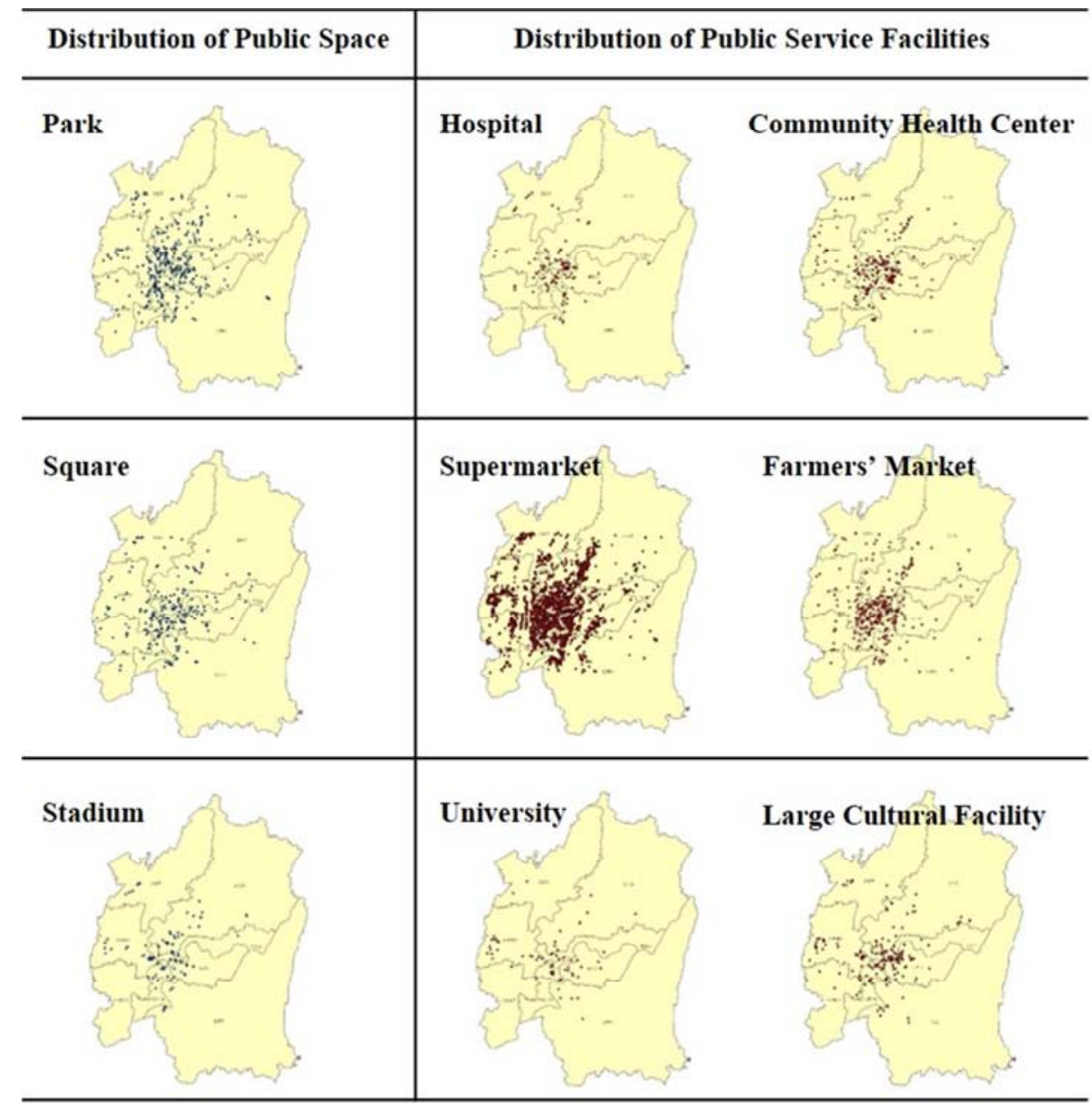

Figure 4. Spatial distribution of various public space and public service facilities in the main downtown districts of Chongqing.

Kernel Density Estimation of public space and public facilities in the main downtown districts was conducted separately by ArcGIS to analyze the layout and hotspots distribution of public space and public service facilities. Comparing the two Kernel Density Estimation layers, it could be seen that the spatial hotspots of public space were in the south of Yubei District and the west of Banan District, while the spatial hotspots of public service facilities were concentrated near the old urban area in Yuzhong District. So there was a spatial dislocation between the hotspots of the two (Figure 5), and the coordination of special layout between public space and public facilities was unsatisfactory in the main downtown districts of Chongqing.

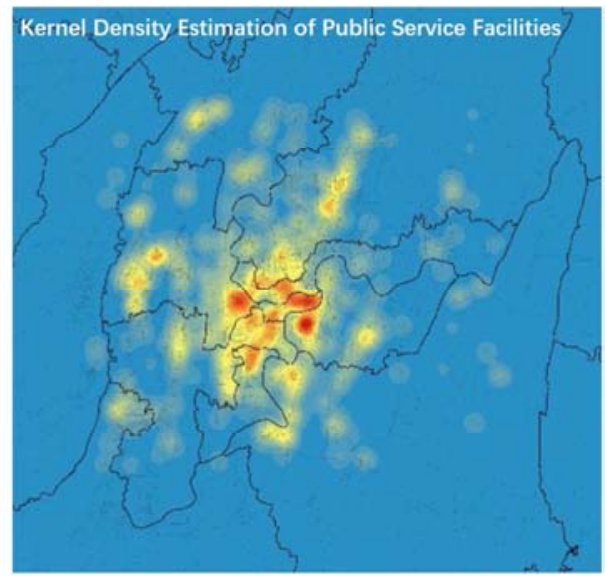

Figure 5. Kernel Density Estimation of public space and in public service facilities the main downtown districts of Chongqing. 


\subsection{The level of Spatial Connection of Public Space and Public Service Facilities Was Low}

Based on POI data and the methods above, the coverage ratio of various public service facilities within the 500-meter service scope of public space was measured, and the 500-meter service scope of public space in the main downtown districts of Chongqing was obtained (Figure 6), as well as, the coverage ratio of various public service facilities in the 500-meter service scope of public space in different districts (Table 2), the overall coverage ratio of public service facilities in different districts (Figure 7), and the distribution of various public service facilities within the 500-meter service scope of public space in different districts (Figure 8).

The overall coverage ratio of public service facilities in the main downtown districts of Chongqing was less than $50 \%$, so the overall level of spatial connection between public space and public service facilities was inadequate. The coverage ratios of the six types of public service facilities varied greatly in different districts, among which the coverage ratio of hospitals was the maximum at $65 \%$, the coverage ratio of educational facilities was the minimum at $35 \%$, while other items were around $50 \%$. The overall coverage ratios varied slightly in different districts, with the lower coverage ratio in the south and the higher coverage ratio in the north in the main downtown districts of Chongqing. Among them, although Yuzhong District lacked public spaces, it had the most significant coverage ratio at $65 \%$ because of the small area and highly concentrated public service facilities. While Banan District and Jiulongpo District had a large number of public spaces, the coverage ratio of public service facilities was lower than the average value of the main downtown districts. It could be seen that in old urban areas, the problem of insufficient public space was more severe but the level of spatial connection between public space and public service facilities was relatively high because of small blocks, dense road network and abundant public service facilities. While in new urban areas, although there were a large number of public spaces, the level of spatial connection between public space and public service facilities was relatively low due to the clustering of public service facilities and the small service scope of public space which was caused by and the sparse road network.

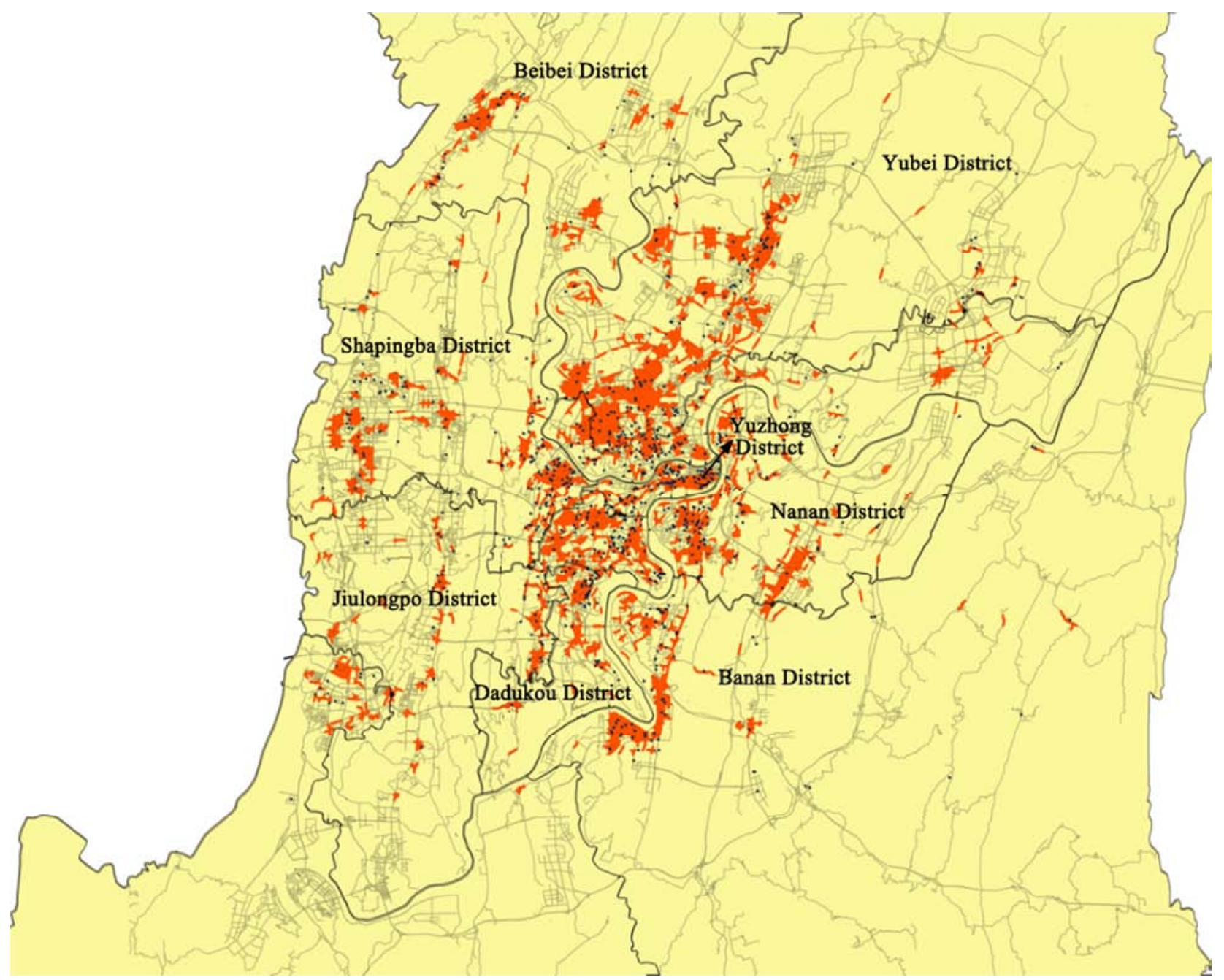

Figure 6. The 500-meter service scope of public space in the main downtown districts of Chongqing. 


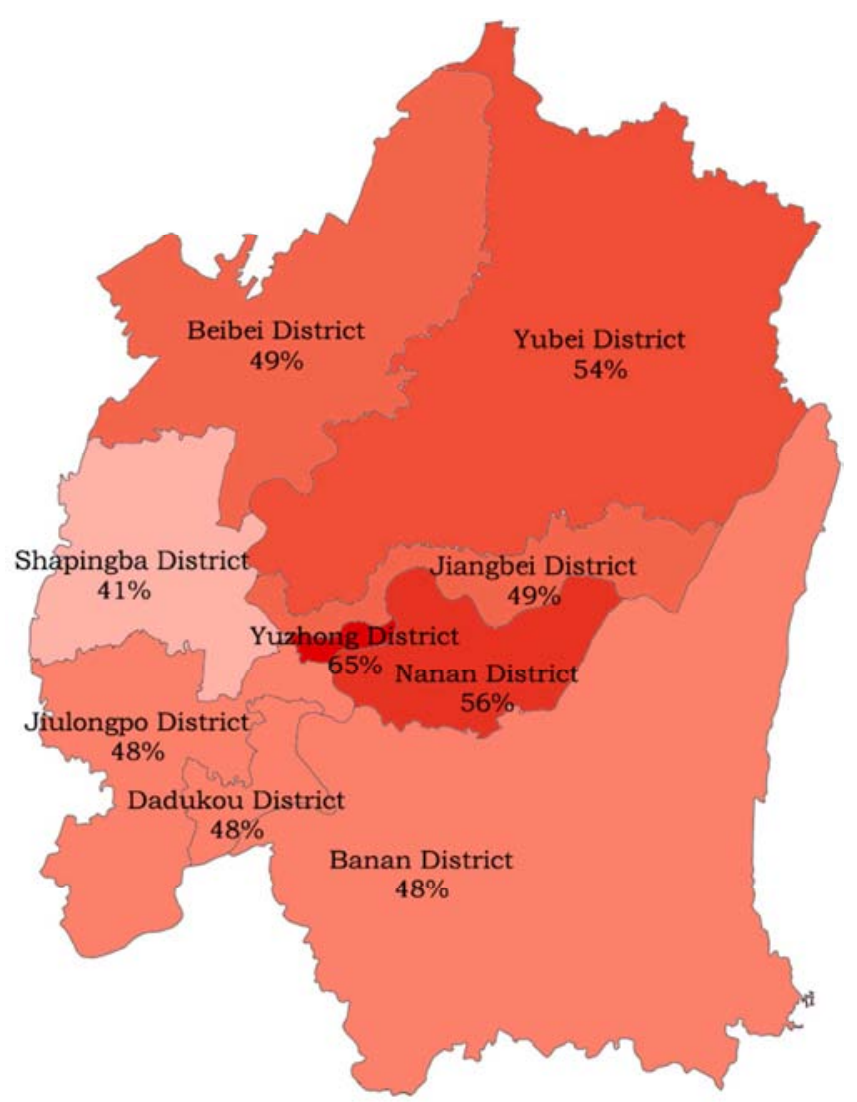

Figure 7. Overall coverage ratio of public service facilities in different districts.

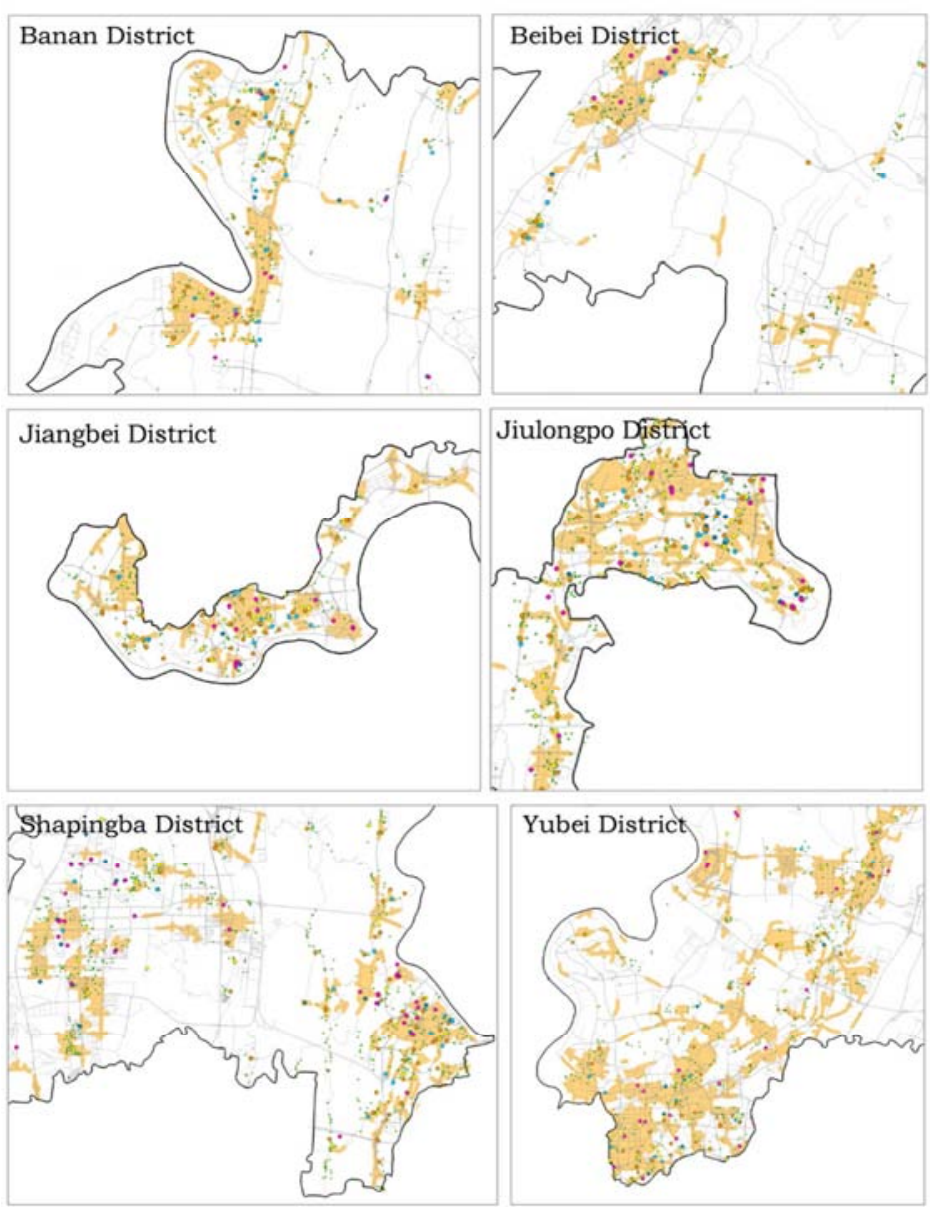




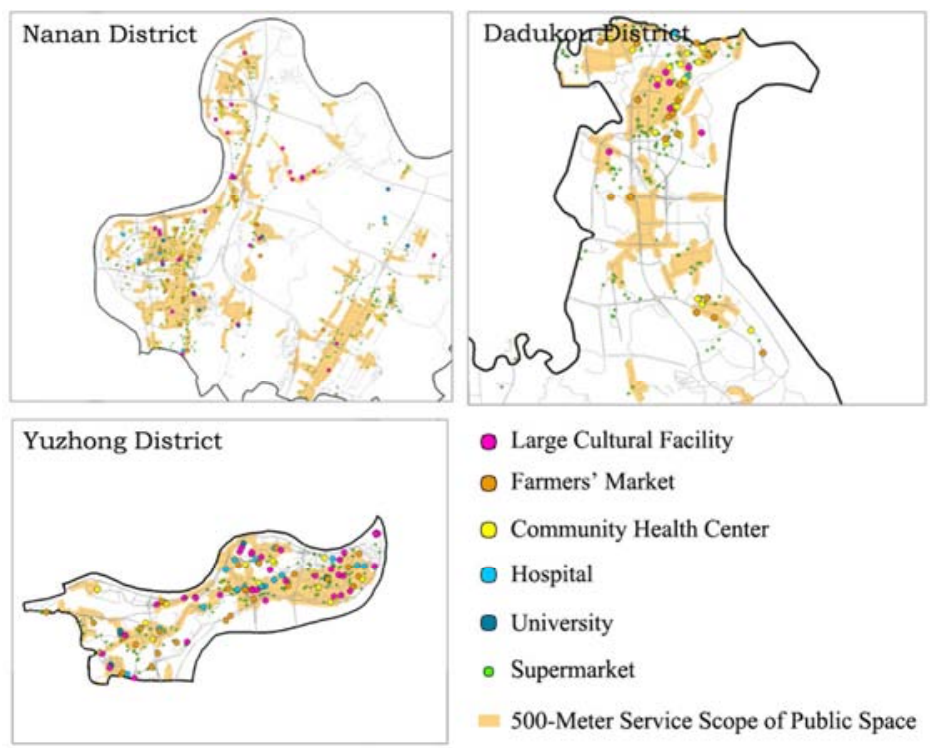

Figure 8. Distribution of various public service facilities within the 500-meter service scope of public space in different districts.

Table 2. Coverage ratio of various public service facilities in the 500-meter service scope of public space in different districts.

\begin{tabular}{|c|c|c|c|c|c|c|c|c|c|c|}
\hline & $\begin{array}{l}\text { Banan } \\
\text { District }\end{array}$ & $\begin{array}{l}\text { Beibei } \\
\text { District }\end{array}$ & $\begin{array}{l}\text { Dadukou } \\
\text { District } \\
\end{array}$ & $\begin{array}{l}\text { Jiangbei } \\
\text { District } \\
\end{array}$ & $\begin{array}{l}\text { Jiulongpo } \\
\text { District } \\
\end{array}$ & $\begin{array}{l}\text { Nanan } \\
\text { District }\end{array}$ & $\begin{array}{l}\text { Shapingba } \\
\text { District } \\
\end{array}$ & $\begin{array}{l}\text { Yubei } \\
\text { District }\end{array}$ & $\begin{array}{l}\text { Yuzhong } \\
\text { District }\end{array}$ & $\begin{array}{l}\text { Total Ratio of } \\
\text { Categories } \\
\end{array}$ \\
\hline \multirow{2}{*}{ Hospital } & $11 / 19$ & $5 / 8$ & $2 / 2$ & $11 / 15$ & $9 / 20$ & $4 / 9$ & $10 / 16$ & $9 / 13$ & $18 / 20$ & $81 / 125$ \\
\hline & $58 \%$ & $63 \%$ & $100 \%$ & $73 \%$ & $45 \%$ & $44 \%$ & $63 \%$ & $69 \%$ & $90 \%$ & $65 \%$ \\
\hline Community & $6 / 12$ & $3 / 5$ & $12 / 22$ & $14 / 25$ & $17 / 25$ & $26 / 38$ & $20 / 43$ & $26 / 40$ & $13 / 19$ & $137 / 229$ \\
\hline Health Center & $50 \%$ & $60 \%$ & $55 \%$ & $56 \%$ & $68 \%$ & $68 \%$ & $47 \%$ & $65 \%$ & $68 \%$ & $60 \%$ \\
\hline \multirow{2}{*}{ Farmers' Market } & $23 / 35$ & $7 / 19$ & $10 / 16$ & $19 / 38$ & $31 / 59$ & $23 / 32$ & $26 / 57$ & $38 / 72$ & $18 / 29$ & $196 / 358$ \\
\hline & $66 \%$ & $37 \%$ & $63 \%$ & $50 \%$ & $53 \%$ & $72 \%$ & $46 \%$ & $53 \%$ & $62 \%$ & $55 \%$ \\
\hline Facility & $45 \%$ & $63 \%$ & $86 \%$ & $75 \%$ & $59 \%$ & $40 \%$ & $57 \%$ & $56 \%$ & $54 \%$ & $55 \%$ \\
\hline \multirow{2}{*}{ Supermarket } & $221 / 471$ & $119 / 248$ & $72 / 166$ & $115 / 252$ & $300 / 630$ & $239 / 426$ & $323 / 830$ & $407 / 771$ & $99 / 153$ & $1938 / 4043$ \\
\hline & $47 \%$ & $48 \%$ & $43 \%$ & $46 \%$ & $48 \%$ & $56 \%$ & $39 \%$ & $53 \%$ & $65 \%$ & $48 \%$ \\
\hline \multirow{2}{*}{ University } & $2 / 5$ & $2 / 2$ & 1 & $0 / 3$ & $1 / 11$ & $3 / 10$ & $7 / 18$ & $5 / 10$ & $4 / 5$ & $24 / 69$ \\
\hline & $40 \%$ & $100 \%$ & 1 & $0 \%$ & $9 \%$ & $30 \%$ & $39 \%$ & $50 \%$ & $80 \%$ & $35 \%$ \\
\hline Total Ratio of & $268 / 553$ & $141 / 290$ & $102 / 213$ & $171 / 349$ & $375 / 774$ & $307 / 545$ & $407 / 1001$ & $503 / 938$ & $174 / 267$ & $2494 / 5039$ \\
\hline Districts & $48 \%$ & $49 \%$ & $48 \%$ & $49 \%$ & $48 \%$ & $56 \%$ & $41 \%$ & $54 \%$ & $65 \%$ & $49 \%$ \\
\hline
\end{tabular}

\subsection{Actual Spatial Connection of Public Space and Public Service Facilities Adjacent to Each Other Was Inconvenient}

Take the First Hospital of Chongqing Medical University and Chongqing Olympic Sports Center in Yuzhong District as the typical example. There was only one block apart between them, but due to the lack of internal connecting passageways, they need to be connected via city arterial roads and city branch roads. As a result, the spatial connection between the two was easily disrupted by the city traffic and was quite unfavorable to the transportation of goods and the control of pandemics (Figure 9). So It could be seen that even if the urban public space and public service facilities were located close to each other, the spatial connection was still inconvenient, due to the lack of consideration for the resource sharing of public space and public service facilities during the urban construction, which was a common phenomenon in Chongqing or other metropolitan built-up areas. And it was disadvantageous to epidemic prevention and control.

\subsection{Summary of the Present Situation}

It could be seen from the above analysis that, there was a large spatial dislocation between the hotspots of public space and public service facilities in the main downtown districts, and the coordination of spatial layout was weak; the overall coverage ratio of public service facilities in the 500-meter service scope of public space in the main downtown districts was less than $50 \%$, and the level of spatial connection was low; the public space and public service facilities adjacent to each other in the main downtown districts generally lacked internal connection channels, and the spatial connection between the two was vulnerable to interference. As a result, due to the spatial dislocation and inconvenient spatial connections, the Joint Disaster Response capacity of public spaces and public service facilities in the main downtown districts of Chongqing was weak. When a significant disaster strikes, it may be arduous for public space and public service facilities to share emergency rescue resources. 


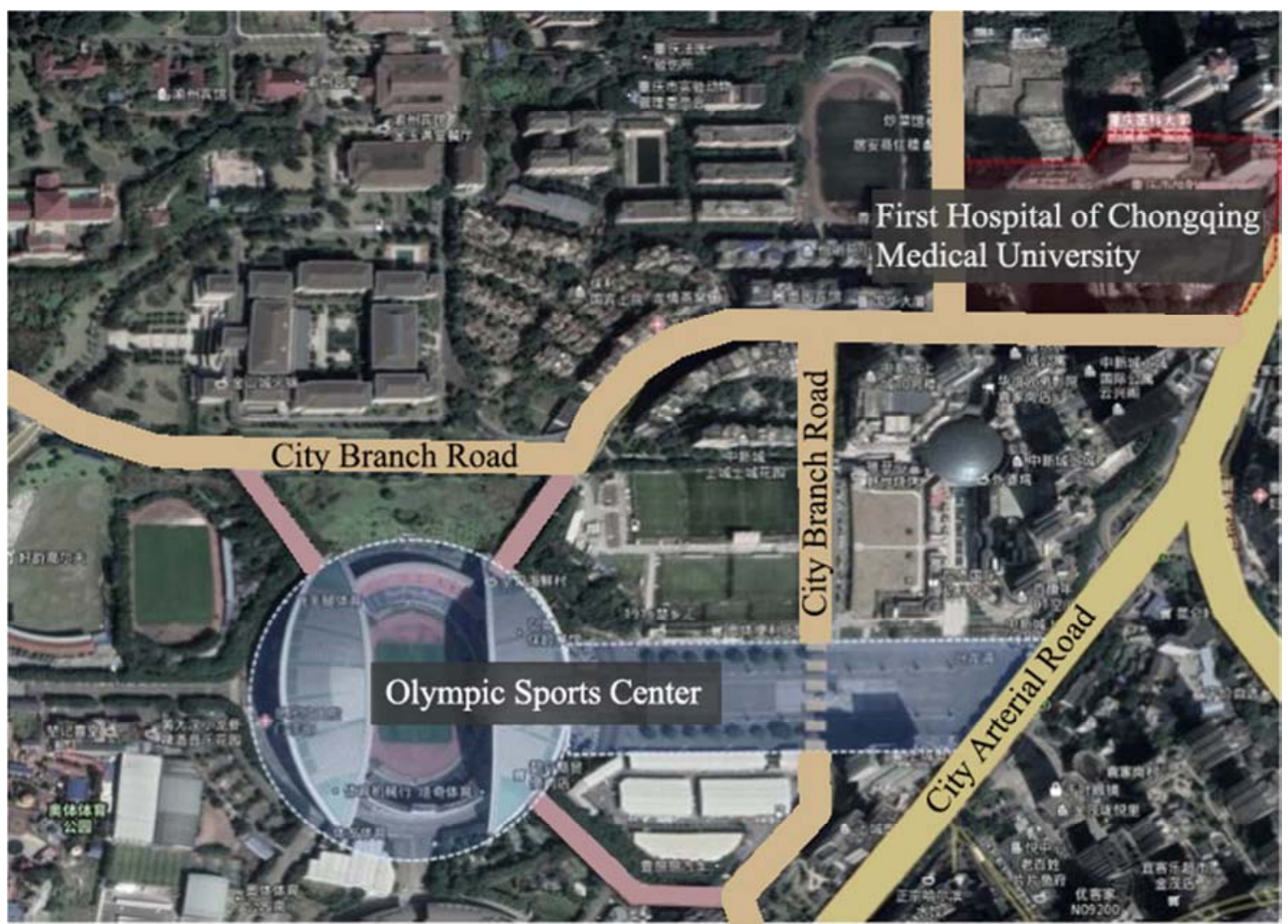

Figure 9. Spatial connection between the First Hospital of Chongqing Medical University and the Olympic Sports Center.

\section{Suggestions for Improving the Joint Disaster Response of Public Space and Public Service Facilities}

(1) Coordinative planning - from "two layers of planning" to "one map"

For a long time, urban planning of public service facilities and public space has been two independent planning items. This has caused a lack of connection between their spatial layouts and difficulties in sharing resources during disasters. In the future, the Joint Disaster Response capabilities of public space and public service facilities should be strengthened at the urban planning level. Firstly, the urban public space and public service facilities, which are important for disaster prevention, should be classified and integrated into comprehensive disaster prevention planning. Secondly, a certain amount of flexible space and white land should be reserved near public service facilities (especially hospitals) to meet the construction needs of emergency rescue sites. Thirdly, the coverage ratio of various public service facilities in the service scope of public space should be increased to enhance both emergency rescue capabilities during disasters.

(2) Scientific assessment - establish evaluation criteria for Joint Disaster Response of public space and public service facilities

It is necessary to use the scientific evaluation criteria to evaluate the Joint Disaster Response capacity of public space and public service facilities. Through the method adopted above, a preliminary evaluation method is proposed. Based on ArcGIS, according to the road-net data, different levels of the service scope of public space can be obtained. Furthermore, from the city, district, and community levels, develop a hierarchical standard for the coverage ratio of various public service facilities in different service scopes of public space. And then, based on the coverage ratio standards, the current planning can be scientifically evaluated and adjusted.

(3) Accessible channel- construct the internal passageway between public space and public service facilities

Urban public space and public service facilities adjacent to each other can exchange resources through the internal passageway to avoid disruption by urban traffic and better prevent the spread of epidemics. For public space and public service facilities to be built in new urban areas, the internal passageway can be reserved in the design. And for public space and public service facilities built in old urban areas, in order to avoid large-scale demolitions, the internal passageway can be constructed from underground and connected with their respective underground garages [19] (Figure 10). 


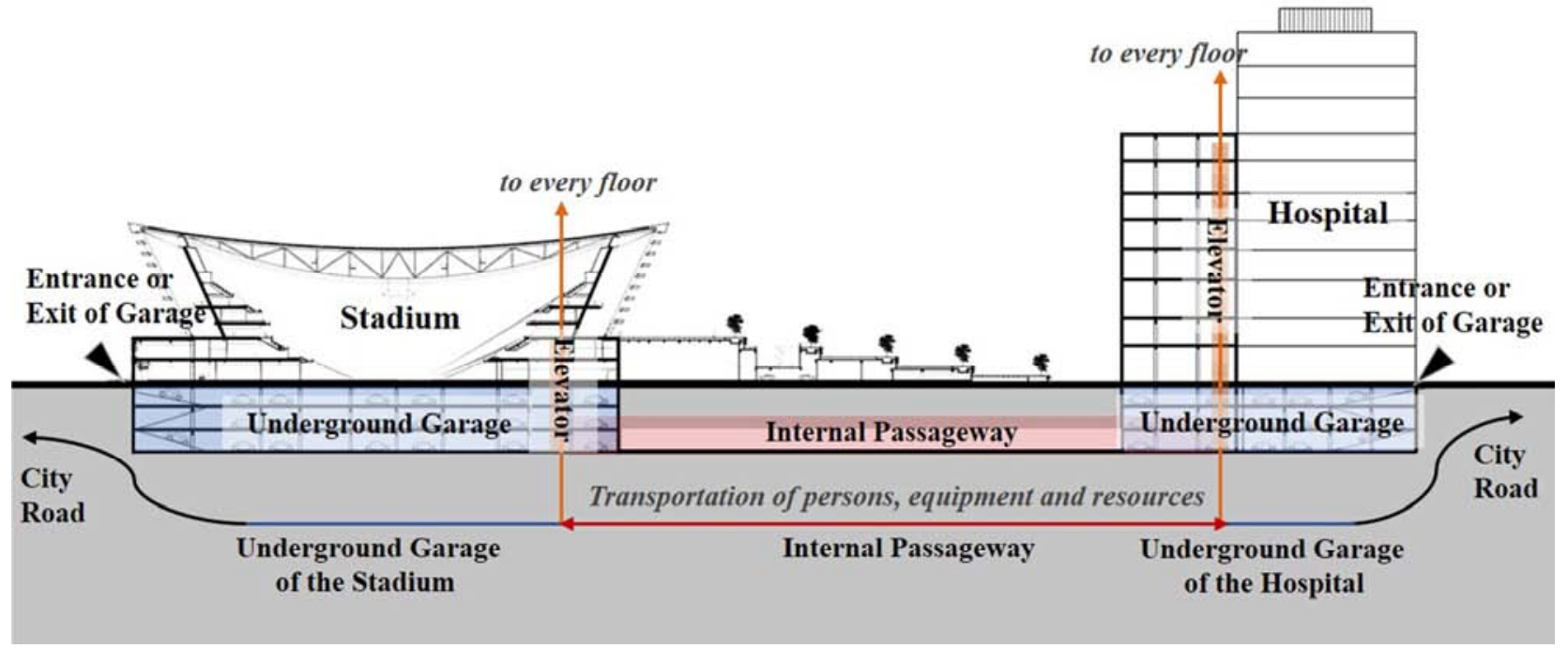

Figure 10. Schematic diagram of underground internal passageway of public space and public service facilities.

\section{Conclusion}

Urban public space and public service facilities are indispensable components of the comprehensive disaster prevention system in metropolises, and they can further improve emergency rescue capabilities through resource sharing during disasters. Taking the main downtown districts of Chongqing as a study case, according to the coordination of spatial layout and the level of spatial connection, this paper evaluated the Joint Disaster Response capacity of public space and public service facilities based on POI data and ArcGIS, found that the spatial layout of public space and public service facilities had a large dislocation and the spatial connection of the two was inconvenient, and finally proposed a strategy for optimizing the Joint Disaster Response capacity of public space and public service facilities in metropolises from three aspects: adjusting the planning system, establishing evaluation criteria and strengthening spatial connections. It hopes to provide ideas and suggestions for improving the urban disaster resilience and the emergency response capacity of metropolises in the post-epidemic era.

\section{References}

[1] Harapan H, Itoh N, Yufika A, et al. Coronavirus disease 2019 (COVID-19): a literature review [J]. Infect Public Health. 2020; 13 (5): 667-673.

[2] A. A. Dawood. Mutated COVID -19 may foretell a great risk for mankind in the future [J]. New Microbes and New Infections, 2020, 35.

[3] Jin Jili. Insights on standardsin 2020 "Two sessions" (English) [J]. China Standardization, 2020 (04): 20-29.

[4] Ashforth Blake E. Identity and Identification During and After the Pandemic: How Might COVID-19 Change the Research Questions we Ask? [J]. Journal of Management Studies, 2020, 57 (8).

[5] Tan Zongbo. Thinking About National Territory Development
Plan Triggered by Public Health Incidents [J]. China Land, 2020 (03): 8-12.

[6] Yu Jianling. Investigation on the Current Situation and Development Countermeasures of Disaster-prevention Green Space in Shanghai [D]. Shanghai Institute of Technology, 2019.

[7] Chen Lijing. Preliminary Study on the Correlation Between COVID-19 Epidemic Situation and Urban Space in Wuhan [A] EBRA, Xi'an University of Architecture and Technology. A New Idea for Starting Point of the Silk Road: Urban and Rural Design for Human: Proceedings of the 14th International Conference on Environment-Behavior Studies (EBRA 2020) [C]. EBRA, Xi'an University of Architecture and Technology: Huazhong University of Science \& Technology Press, 2020: 7.

[8] Zhao Gong. Practice and Thinking on Strengthening Safety Management of Public Facilities in Megacity [J]. Urban Management and Science \& Technology, 2021, 22 (04): 10-13.

[9] Tang Liuyu. Research on the Functional and Regional Pattern Optimization of Chengdu under the Background of Metropolitan Area [D]. Southwest Jiaotong University, 2020.

[10] Zander S Venter, Venter Zander S, Barton David N, Gundersen Vegard, Figari Helene, Nowell Megan. Urban nature in a time of crisis: recreational use of green space increases during the COVID-19 outbreak in Oslo, Norway [J]. ENVIRONMENTAL RESEARCH LETTERS, 2020, 15 (10).

[11] Lin Zhanpeng. Research on the Disaster Prevention Parks in High- density City_ C Case Study of Hong Kong [J]. Chinese Landscape Architecture, 2008 (09): 37-42.

[12] Jiang Yinghong, Shen Leihong. Study on Planning Strategies of Resilient and Health Open Space in Cities under the Combination of Epidemic and Disaster [J]. Shanghai Urban Planning Review, 2021 (02): 76-81.

[13] Tan Zhuolin, Lu Ming. Early Warning, Response and Recovery: Research on Planning Strategies for Responding to Public Health Emergencies from the Perspective of Urban Resilience [J]. Journal of Human Settlements in West China, 2021, 36 (04): 59-65.

[14] Wang Fei. Study on Resilience Improvement of Urban Community Disasters in the Post Epidemic Period [D]. Shandong University, 2021. 
[15] Li Huizhi, Yi Dali, Li Gaoming. Comparative Study on Assessment Methods of Epidemic Risk of COVID-19 in Chongqing [J]. Journal of Chongqing Medical University, 2020, 45 (07): 870-875.

[16] Zeng Wei, Zhao Yingjie. Strategy of Comprehensive Disaster Prevention Planning in Mountainous Cities [J]. Science \& Technology Review, 2021, 39 (05): 17-24.

[17] Tang Fanghua, Mo Wenbo, Zhang Xi, Zhou Songlin. Spacial Distribution of Public Service Facilities Based on POI Data [J]. Urbanism Architecture, 2017 (27): 35-39.
[18] Zhao Yanyun, Zhang Bo, Zhou Fang. Research on Spatial Measurement of "15-minute community life circle" in Beijing Based on POI [J]. The World of Survey and Research, 2018 (05): 17-24.

[19] Zou Yun, Jiang Shuping, Li Yong. Planning of Rapid Underground Passage in Yuzhong District of Chongqing [J]. Technology of Highway and Transport, 2009 (01): 107-112. 